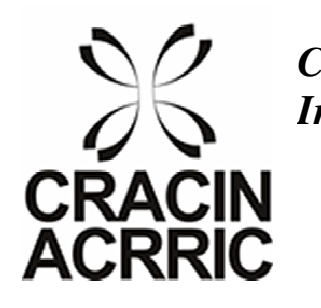

Canadian Research Alliance for Community

Innovation and Networking (CRACIN)

Alliance canadienne de recherche pour le réseautage etl'innovation communautaires

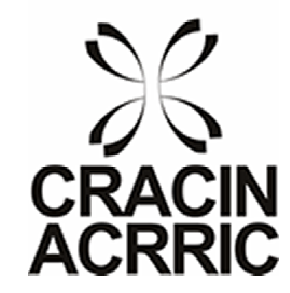

\title{
Sharing Wireless Internet in Urban Neighbourhoods
}

\author{
Matt Wong \\ University of Toronto \\ Andrew Clement \\ University of Toronto
}

January 2007

CRACIN Working Paper No. 19
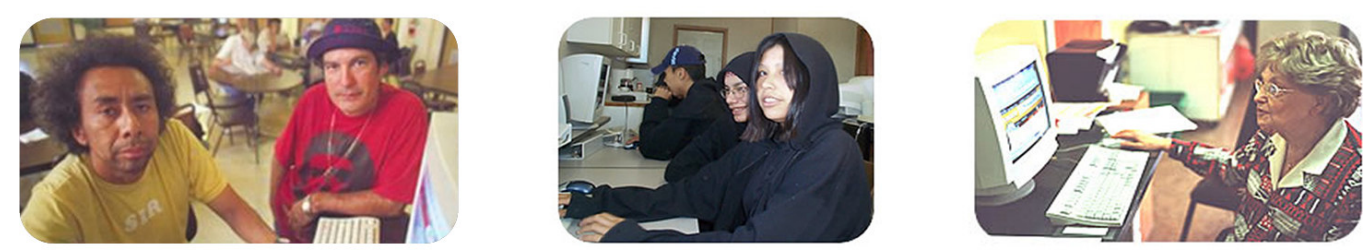

Www.cracin.ca

-1 - 


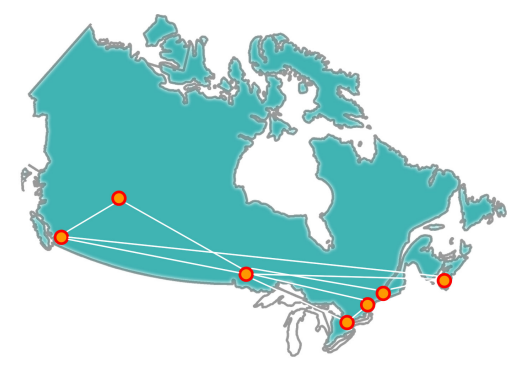

\section{About CRACIN}

The Canadian Research Alliance for Community Innovation and Networking (CRACIN) is a four-year partnership between community informatics researchers, community networking practitioners and federal government policy specialists, funded by a grant from the Social Sciences and Humanities Research Council (SSHRC). CRACIN brings together researchers and practitioners from across Canada, and internationally, to undertake case studies and thematic research on the enabling uses of new information and communication technologies (ICTs) by communities, and to investigate Canada's national programs and policies for promoting the development and public accessibility of digital networks, applications and services.

CRACIN Working Paper Series Editor: Graham Longford, Post-doctoral Research Fellow, Faculty of Information Studies, University of Toronto

\section{Suggested citation:}

Wong, Matt, \& Andrew Clement (2007) "Sharing Wireless Internet in Urban Neighbourhoods," CRACIN Working Paper No. 19, January 2007 Toronto: Canadian Research Alliance for Community Innovation and Networking.*

* to be presented at the 3rd International Conference on Communities and Technologies, Michigan State University, East Lansing, Michigan, June 28-30, 2007.

For further information or to order hard copies of CRACIN materials, contact:

Project Administrator

Faculty of Information Studies

University of Toronto

140 St. George Street, Rm 310

Toronto, Ontario M5S 366

Phone: (416) 978-4662

Fax: (416) 971-1399

Email: cracin@fis.utoronto.ca

Web: www.cracin.ca 


\begin{abstract}
With the development and commercialization of wireless ('WiFi') technology for home Internet use in the last several years, the opportunity for users to share Internet access easily with one another has become possible. While this sharing began informally, even surreptitiously, it has recently become widespread and more formal with prominent announcements of city-wide wireless network deployments. However, while there are many benefits claimed for these services, such as broader coverage, improved access and lowered cost, relatively little is known about how people regard sharing wireless Internet services. Using both quantitative and qualitative methods, this research investigated the range of attitudes towards such sharing among urban wireless users. Our research revealed generally positive feelings about the benefits of sharing, especially when using others' signals, but serious reservations about making their own signals open for use by strangers. These findings have implications for developing both community-wide infrastructure as well as local, ad-hoc systems. They also provide the basis for several design features that would promote sharing, including security measures, privacy protection, cost reduction, bandwidth prioritization and reciprocal notification.
\end{abstract}




\section{Introduction}

Over the last decade, Internet use in countries around the world has grown dramatically. This is especially true in Canadian cities, which is the focus of this paper. Canada is widely acknowledged as having strong broadband penetration rates (Frieden, 2005; Chukwuma, Furnell \& Ghita 2002; Wu, 2004) and the statistics available from Canadian census data paint a picture of Internet growth across the country. Residential households are increasingly adopting Internet technology and using it in their daily activities. In large urban centres internet usage rates approach $80 \%$, overwhelmingly via broadband connections (Statistics Canada, 2006). Users commonly report using the Internet for many facets of their lives including communication, entertainment, and information seeking in the home, at work and school (Dryburgh, 2001).

One development in particular that has had a hand in the growing use of Internet services is the standardization of wireless Internet technology. Wireless Internet, commonly abbreviated as WiFi for 'wireless fidelity,' is based on the IEEE 802.11 group of protocols. Since the introduction of the 802.11 'b' protocol in 1999, there has been rapid growth and development in the wireless market with wireless technology such as routers and antennas becoming both abundant and affordable for the home consumer. Schmidt and Townsend (2003) noted that in 1999 wireless base stations cost at much as $\$ 1000$, but only four years later had dropped to $\$ 100$. Several authors have attributed this drop in consumer cost with the explosion in home networking (Damsgaard, Parikh \& Rao, 2006). Also, wireless 'hotspots' in public spaces such as cafes, airports, and on university campuses have become more available. While of practical benefit to urban areas, WiFi has also been shown to be very useful as a means for connecting disadvantaged, rural, isolated, or smaller communities where cabling costs may be prohibitive (Tully \& Riekstins, 1999; James, 2001).

The effect that this explosive growth of wireless networking has had around the world is striking. It is roughly estimated that some 200 million Wi-Fi chipsets had been sold in 2005 (Shah \& Sandvig, 2005, pg.7). While wireless networking originally began as a way to extend existing wired networks without laying cable, it has since been used as a way to provide access where it was never thought of before. Now, there is growing ubiquity and signals flow out to other people's areas and public spaces. These signals often overlap one another and create dense 'clouds' of wireless coverage. These clouds have implications for both ad-hoc local sharing between neighbouring homes, and community-wide access infrastructure projects, two common areas of interest. Andersen (2003) described this evolving ubiquitous use as a new paradigm and speculates that "the future belongs to small, connected devices that will wirelessly allow the user - and the technology - to self-organize, creating something smart out of many small and simple nodes and connections" (para.12).

However, WiFi signal sharing is often inadvertent, the result of networks being left 'open'. Indeed, users are often cautioned about leaving their networks unprotected for fear of hacking, privacy invasion, or unauthorized use (Shah \& Sandvig, 2005). How do individuals feel about sharing in an environment of such concerns? Are people interested in sharing?

What are some of the issues that are important for wireless users? Under what conditions, if any, would people be willing to share? How are people who are currently sharing doing so? What motivates them to do this? In terms of community-wide access projects, what are some of the issues that arise from the growing ubiquity of WiFi signal access? Many communitywide projects also make broad claims about addressing inequality of access while presuming communitarian values. These too need to be examined in light of wireless users' attitudes towards sharing. 
In this paper we report on some of these attitudes as they were investigated among wireless users in urban, residential neighbourhoods of Toronto, Canada. The paper begins with a brief discussion of wireless Internet sharing, some background motivations for wireless community projects, and an overview of the attitudes we anticipated among participants. This is followed by the study's methodology and its findings. The discussion section integrates these findings to shed light on how community-wide infrastructure and local, ad-hoc projects might be developed and concludes by identifying some of the key design features to enable viable sharing.

\section{Wireless Internet}

Wireless communication is a process whereby radio waves are systematically generated and then emitted through an antenna. The radio waves used by various devices operate in different frequency ranges that make up part of the spectrum of electromagnetic radiation. Radio waves propagate through the air where they are received by another device and the signal is decoded. In 1997, the Institute for Electrical and Electronics Engineers (IEEE), created the 802.11 standard, which listed a number of protocols related to transmitting data over the 2.4 gigahertz $(\mathrm{GHz})$ band. In many countries, the $2.4 \mathrm{GHz}$ band of the radio spectrum is license-exempt (the Industrial, Scientific, and Medical band) meaning that an operator does not require a government license prior to use. This band also includes devices like cordless phones, microwave ovens, and garage door openers. In 1999, the IEEE added the $802.11 \mathrm{~b}$ standard, which offered data rates up to 11 megabits per second (mbps). Along with other enhancements, this set the standard for numerous devices to be created to take advantage of this wireless band. In the years since, higher data rate standards such as 802.11a and 802.11g have been added, although 802.11b is still common. In conjunction with the use of the software protocols for Transmission Control (TCP) and Internet (IP), wireless devices of many kinds now exist to transmit and receive Internet signals. A common approach for many home users is a wireless router, acting as an Access Point (AP) that broadcasts a signal connecting a number of computers. When several devices can communicate and share information between each other, they form a Wireless Local Area Network (WLAN). When the wireless router is then connected to a back-end Internet connection, such as a DSL or cable connection, computers in the WLAN can send and receive Internet traffic. The wireless router identifies itself to other devices through its network name, also known as the Service Set Identifier (SSID). This technology is now common enough to be available at work places, public spaces, universities, and households, to name a few locations. One of the strong points of wireless technology is its ability to be deployed nearly anywhere and, under the right conditions, to provide signal transmission over long distances.

Furthermore, with the ability to broadcast over a range (roughly 30 meters indoor and 60 meters outdoor) compared to having a single wired connection point, users equipped with portable devices can also receive signals at a distance from the AP. Wireless devices moving in and out of range, disappearing and then re-appearing (i.e. turning on/off/on), and generally being transient in nature during a session is often called ad-hoc networking. Ad-hoc generally refers to support for spontaneous communication among mobile and fixed terminals whenever there is the physical possibility to do so (Remondo \& Niemegeers, 2002). The first wireless networks were of this kind.

When a wireless AP is systematically used to extend an existing wired network, this is considered 'infrastructure networking' (Marks, Gifford \& O'Hara, 2001). Infrastructure 
networking can lead to the kind of community-wide wireless networks that have been proposed in numerous cities throughout the world. In these networks, rather than a series of disparate nodes that remain unconnected to one another, infrastructure nodes communicate together as part of a single large, extended network. This is often accomplished using 'mesh' networking technology, which relies on these overlapping, linked nodes to create a more reliable, redundant network (Akyildiz \& Xudong, 2005). A large infrastructure wireless network may use telephone or light poles to house their wireless nodes, for example.

Infrastructure and ad-hoc networks represent the extremities of the spectrum of wireless networking possibilities, and as such present different kinds of challenges, both technical and social. Ad hoc networking is arguably simpler, being as easy to create as leaving a home wireless router in an unprotected state. Indeed, this is the default setting of new commercially purchased routers, which has played an important role in the evolution of shared home wireless broadband (Shah \& Sandvig, 2005). In this state, other wireless devices like laptops can detect the signal and use it to access the Internet. Alternatively, shared access can be granted by providing users of the signal with the Wired Equivalent Privacy (WEP) key that corresponds to the particular SSID. Another form of regulated sharing uses captive portal technology, in which users are redirected to a log-in page requiring a password. With all these forms of sharing some degree of trust and goodwill is expected of the user because all participants of that wireless network collectively share the bandwidth capacities of the connection. This can become more of an issue when access is shared among strangers (the 'open' case) versus trusted or at least authenticated parties (the password case) because with anonymous strangers there may be no control over their usage. Sharing in well-resourced infrastructure networking, as exemplified by some of the city-wide WiFi projects such as San Francisco or Toronto, may pose less of an issue with high capacity backbones mitigating bandwidth contention. Furthermore, administration of the network and granting access would likely be handled in a systematic and centralized way that prevents some forms of abuse, while creating other vulnerabilities with the possibility of system-wide compromise or failure.

\section{Wireless Internet and Community Networking}

Considering the increasing number of wireless projects that have been announced worldwide (Vos, 2005) and the high-profile nature of deployments in major North American cities, interest in deploying community and municipal networks seems to be developing rapidly. For example, Tapia and Ortiz (2006) identify nearly 360 municipal wireless projects in the United States. There are likely at least this number of smaller, less formalized, grass-roots community initiatives. Together, they represent a burgeoning area within community informatics -- "the application of information and communications technologies to enable community processes and the achievement of community objectives" (Civille et al., 2002, pg.7).

The interests and objectives of community and municipal wireless Internet projects can be loosely grouped into two broad goals - improving access through wider availability and lowered costs, and improving democratic ownership over public goods, in part by

gaining control of communications infrastructure that would otherwise be in the hands of private telecommunications companies (Gibbons \& Ruth, 2006; Goth, 2005; Sandvig, 2004; Lentz, 1998). 
Accessibility and cost problems present distinct challenges and represent some of the major concerns of community and municipal network advocacy groups. Souter (1999) noted that lack of access is a problem for communities because "access to ICTs [Information and Communication Technologies] and their potential for enhancing welfare and community involvement is increasingly important for communities seeking to raise their quality of life, engage in determining the policies that affect them, or diminish differentials that underpin their disadvantage" (pg.409). In particular for rural and isolated communities, Internet access often represents a key means of connection to information from beyond local borders, as well as access to government services, such as online medical advice and interactive education (Williamson, 1999, pg.186). Community and municipal network projects often aim to address these challenges through the deployment of their own publicly controlled networks, rather than resorting to private providers.

Wireless plays a particularly relevant role in these projects because by enabling overair transmission of signals instead of digging up ground and laying cables, it can radically reduce costs. In rural environments, especially open areas or flat terrain, directional antennae mounted on towers can beam signals in a point-to-point relay, reducing the need for cables throughout the entire network. In urban environments, especially densely packed housing complexes, wireless can be used to cheaply propagate access through buildings rather than individually laying cables within them. Community and municipally organized networks could also benefit from economies of scale by buying bandwidth in bulk or reducing service costs to increase subscriptions. Indeed, the mandate of community or municipal organizations in these kinds of situations would be to address what they regard are the failings of private providers with respect to elements of society that treat as unprofitable. Gibbons and Ruth (2006) suggest that "with the twin challenges of low availability of broadband service to many poor areas and a relatively high unit price, it would seem that many municipalities do, in fact, need a tailored service aimed at empowering those who can't currently benefit from broadband" (pg.68). Sandvig (2004) adds that in the case of wireless co-operatives, perhaps they can be used "as an important symbiote to other infrastructure, providing services in commercially undesirable areas" (pg.599) and in this way maybe address public goals that are of little interest to corporations.

Along with greater access and ownership, there may be additional benefits for these community networks. Examples of these 'digital communities', such as the Blacksburg Electronic Village (Casalegno, 2001) and Netville (Hampton \& Wellman, 2003), demonstrate some of the benefits of using computer technologies to promote community organization and relationships. These benefits include facilitating communication through email lists and local content web pages. Such opportunities can improve social interaction and inclusion among members of a community. Indeed, even smaller scale operations like opening up one's wireless network to neighbours may foster improved social relationships, above and beyond the benefits of cost-sharing.

\section{Attitudes Towards Sharing and Wireless}

The lists of potential benefits of wireless Internet sharing run the danger of painting too onesided a picture of its adoption -- creating an almost ideal vision of its deployment and potential use. Neglected in the discussion so far is any attention to how the parties to wireless sharing view this arrangement. It is therefore important to consider what kinds of attitudes may exist or be anticipated when it comes to addressing these topics. Before asking target groups of users how they feel about sharing and wireless, examining previous work in a 
variety of fields, such as decision making, the diffusion of innovations, marketing, and community informatics case studies can help us anticipate some of the more common sentiments.

For example, people's attitude towards a product or service is often influenced by external factors, such as other people and media sources. These sources may affect how an individual may perceive something and lead to changes in their personal opinions. Rogers (2003), called these sources 'change agents' from his earlier, original work on the diffusion of innovations. Consider that in the wireless case, individuals may be swayed by change agents to adopt it for its mobility, but at the same time warned to encrypt their networks to prevent signal theft or hacking attempts. This may further affect individuals depending on their personal disposition towards the Internet. Individuals accustomed to a dedicated home connection may be reluctant to risk a reduction in their bandwidth or service slow-downs through sharing.

When considering whether to adopt a recognizably superior infrastructure service to replace their current ISP, customers may be deterred by high 'switching costs', defined as "the psychological, physical, and economic costs that consumers face in switching between technologies" (Pae \& Hyun, 2006, pg.19). Such costs may include the hassle of changing email addresses, purchasing new equipment, or entering into a new contractual agreement. Particularly with telecommunication or cable companies offering bundled services (e.g. television, phone, and mobile service agreements), it may be increasingly difficult to justify the switch to another service provider, even one with the benefits of wireless networking.

Finally, when addressing issues of sharing, it is important to consider attitudes and perspectives about trust, particularly with neighbours or other members of the community. Individuals may not want to share with others due to a wariness of how others may use their connection or hesitation around computer privacy and security. On the other hand, splitting costs or helping out neighbours who may not be able to afford Internet may be powerful motivators to share.

\section{Methodology and Findings}

The study made use of both qualitative and quantitative data collection, carried out in two distinct phases. First, we conducted radio surveys of wireless signals in two urban neighbourhoods. Next, we recruited current wireless users for two successive questionnaire surveys, followed by in-depth interviews with selected questionnaire respondents.

\section{Radio Surveys}

In order to assess the intensity and forms of wireless use in residential neighbourhoods, we first conducted wireless radio surveys. These were radio surveys in the technical sense, where a receiver was used to passively detect wireless Internet radio signals of the $802.11 \mathrm{~b} / \mathrm{g}$ standard (11 and $54 \mathrm{mbps}$, respectively) operating in the $2.4 \mathrm{GHz}$ frequency range. The purpose of these surveys was to get an idea as to the kind of wireless signal density available in these two areas. Our study was interested in determining to what extent wireless Internet was used in these residential neighbourhoods. The data were collected using a number of tools. A HP-Compaq TC4200-tablet PC with an integrated Intel PRO/Wireless 2200BG Network adapter acted as the receiver. The laptop ran the freely available application Network Stumbler, Version 0.4.0 (Build 554). The laptop was placed, powered on and running the application (NetStumbler), inside a backpack and one of the researchers walked up and down the streets in the chosen neighbourhood. A Pharos GPS receiver (a packaged accessory from Microsoft Streets \& Trips 2005 edition) was connected to the laptop to 
provide GPS coordinates. The radio surveys were conducted in two downtown-Toronto residential areas, primarily selected for convenience. The first survey zone constituted a roughly $1 \mathrm{~km}^{2}$ area while the second was approximately $0.16 \mathrm{~km}^{2}$. These two zones can be characterized as older, urban Toronto neighbourhoods, and as such were typical of large areas of the residential city core. Both were relatively affluent in that zone one had median family income equal to the average for Toronto, while zone two had above average median income.

The results in Table 1 present the findings from the two radio surveys that were conducted.

Table 1. Wireless radio survey results

\begin{tabular}{lr}
\hline Zone One $\left(1 \mathrm{~km}^{2}\right)$ & \\
\hline Number of named networks detected & 219 \\
Number of encrypted named networks* $(\mathrm{N}=219)$ & $127(58 \%)$ \\
Number of unencrypted named networks** $(\mathrm{N}=219)$ & $92(42 \%)$ \\
$\begin{array}{l}\text { Number of unencrypted named networks w/ default44(46\%) } \\
\text { SSID*** }(\mathrm{N}=92)\end{array}$ \\
\hline Zone Two $\left(0.16 \mathrm{~km}^{2}\right)$ & 77 \\
\hline Number of named networks detected & $37(48 \%)$ \\
Number of encrypted named networks* $(\mathrm{N}=77)$ & $40(52 \%)$ \\
Number of unencrypted named networks** $(\mathrm{N}=77)$ & $19(40 \%)$ \\
Number of unencrypted named networks w/ default & \\
SSID $* * *(\mathrm{~N}=40)$ &
\end{tabular}

* encryption schemes included WEP, WPA, AES

** unencrypted does not necessarily mean accessible, there may still be an password-based $\operatorname{login}$

*** default SSIDs were interpreted from known manufacturer names such as Linksys, DLink, SMC, and 'default', however, care should be exercised with this value

These results indicate fairly high wireless density in these urban areas with an average of 206 named networks per square kilometer. In zone one, with approximately 1496 houses, this represents about 1 antenna for every 7 houses. In zone two, with approximately 476

houses, this is 1 antenna for every 6 houses. Of the networks detected an average of 53\% were encrypted. While an average of $47 \%$ were unencrypted, 63 networks were in their original 'open' default state, representing about $22 \%$ of the 296 networks detected. This conversely suggests that $78 \%$ of the networks had been modified by their owners in some way. 69 signals (or 24\%) had modified names but were left un-encrypted. From their names it appears there were few that used captive portal technology and so likely indicate some explicit willingness to share unrestrictedly.

\section{Questionnaires and Interviews}

The second phase of the study utilized two online questionnaires and a number of one-on-one interviews with selected questionnaire respondents. The first questionnaire was a short, webbased online survey that contained 15 questions pertaining to Internet and wireless use (as well as participant contact information). The primary objective in using the short 
questionnaire was to produce a general picture as to what kind of Internet service individuals were using at home by asking questions about their Internet provider and how long they had had Internet access for. It was designed to determine whether these Internet users were using wireless, which devices they were using to connect to it, and whether they were sharing their connections. We were interested in learning these preliminary aspects of individuals' Internet and wireless use in order to provide a broad foundation from which to base the more detailed questionnaire on. A total of 58 people responded to the short questionnaire. Participants were solicited via flyers distributed in the University area, as well as the two radio survey zones. Participants were also solicited from the Faculty of Information Studies mailing list, and the Department of Computer Science electronic forum. A Toronto-based cooperative ISP called Wireless Nomad also assisted in recruiting by displaying a link to our research website on their own website and among their subscribers. The questionnaires sought individuals who were currently using wireless Internet at home, school, or work.

The second questionnaire was also a web-based online survey that was significantly more detailed than the first one and contained 42 questions pertaining to Internet and wireless use, and seven questions about personal information. The long questionnaire would be used to form the bulk of the data on wireless Internet use and sentiment, as well as key questions on attitudes towards Internet sharing. 43 participants from the first questionnaire indicated a desire to continue participating in the study. However, a total of 33 participants eventually responded to the long questionnaire for a $77 \%$ response rate.

From the participants of the second questionnaire, approximately half were solicited for potential participation in in-depth interviews. These individuals had indicated a willingness to conduct interviews on their questionnaire comments or had left many additional comments on the questionnaire forms (suggesting they had to more offer the study). In fact, the study was interested in speaking to individuals who reflected a range of opinions on wireless Internet use and sharing, although no particular attitudes towards it (either supportive or unsupportive) were sought. The interviews were semi-structured and lasted for approximately one hour. They were conducted at the University among nine participants who were ultimately available to be interviewed.

Since the questionnaires and interviews asked a wide array of questions on the issue of wireless Internet use and sharing, the results in the following tables summarize some of the key questions and responses. The demographic data for the second questionnaire is shown below (Table 2). 
Table 2. Demographic data from the second questionnaire

\begin{tabular}{ll}
\hline Gender $(\mathrm{N}=32)$ & \\
\hline Male & 23 \\
& $(72 \%)$ \\
Female & $9(28 \%)$ \\
\hline Age $(\mathrm{N}=33)$ & 25 \\
\hline $20-29$ & $(76 \%)$ \\
$30-39$ & $5(15 \%)$ \\
$40-49$ & $2(6 \%)$ \\
$50-59$ & $1(3 \%)$ \\
\hline Employment status $(\mathrm{N}=33)$ & 14 \\
\hline Employed full time & $(42 \%)$ \\
& 16 \\
Full time student & $(48 \%)$ \\
& $1(3 \%)$ \\
Not working & $2(6 \%)$ \\
Combination of work and school & \\
\hline Highest level of education attained \\
(N=33) & $8(24 \%)$ \\
High school diploma & $(52 \%)$ \\
College diploma or undergraduate 17 \\
degree & $8(24 \%)$ \\
Graduate degree & $9(23 \%)$ \\
\hline Yearly household income (N=30) & 14 \\
\hline Less than \$25,000 a year & $(47 \%)$ \\
\$25,000 - \$54,999 a year & \\
More than $\$ 55,000$ a year & \\
\hline
\end{tabular}

As the demographic data suggest, respondents can be characterized as predominantly young, affluent, educated males. Slightly more respondents were full time students rather than employed full time. Clearly, these results are not characteristic of the general Toronto population, however they may be more indicative of the kind of population who use wireless Internet.

Participants were asked to rank their concerns with using Internet and wireless Internet. Figure 1 shows this ranking of important wireless Internet concerns.

For wireless access, security and reliability were tied for the number one most frequently appearing concern. In the wireless context, security was described by example as "people cannot access your network or use your connection" and signal reliability as "the strength and quality of the radio signal, lack of interference". 


\section{Fig. 1. Ranking of wireless Internet use concerns}

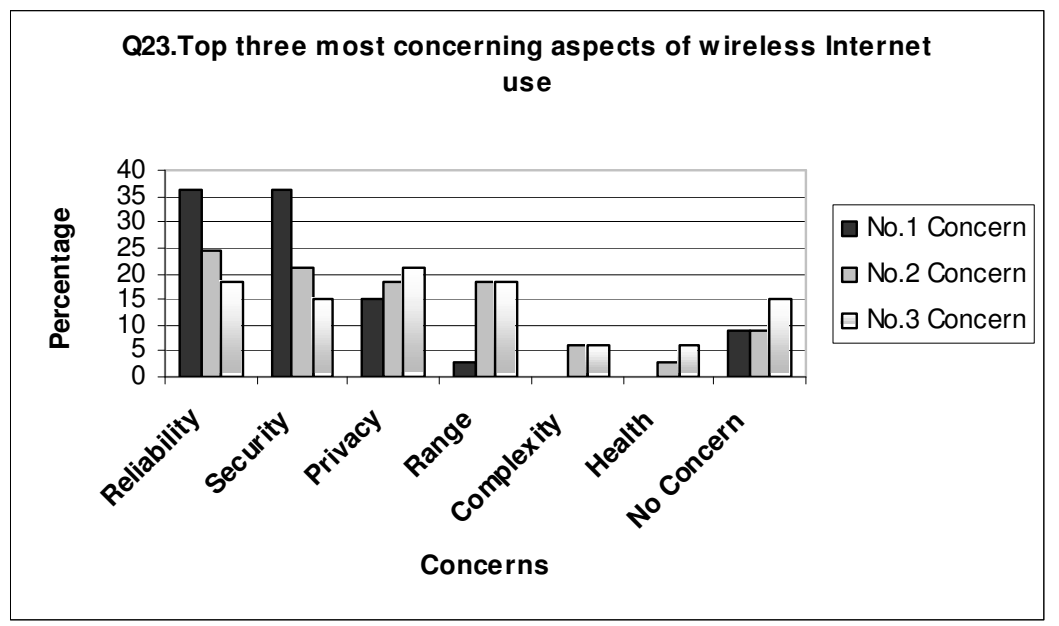

A few comments in the interviews may shed some light on why this emphasis was placed on security. Interviewee A said, "if someone that I didn't know was [using my connection] and I didn't know why [or] what they were up to...that would be a concern" (19:53). Interviewee E said about unauthorized access, "I think that however you slice it, then I would feel a little bit like "wait a second, you're stealing from me" (25:15). Interviewee $\mathrm{H}$, who personally felt that she had been affected by unauthorized access said "I would have said it's like a radio station, you're just picking up someone's signal and there's no harm...but now that I see you're using someone else's bandwidth and it...slows down other people's connections, I think I feel differently about it" (22:27).

The importance of reliability to respondents was a key finding in this study. Many respondents felt strongly about reliability, as demonstrated by their question responses and comments, or bringing up the issue themselves (in the interviews). For example, respondents commented that one of the reasons they would use other people's wireless signals would be when their own failed on them. One respondent commented that "on the rare occasions when our router's signal strength falls for a moment and I get disconnected on my laptop, I use the other people's signals as a brief backup to continue whatever I'm doing"; another said that "once my own DSL line was down, but my neighbours wireless was up." Reliability was also found to be more important to participants than who their provider was. That being said, most participants felt that their current connections were of at least moderate value, and were mostly satisfied with their providers.

When it came to sharing, our participants appeared resistant if they were not informed ahead of time. Conversely, participants were also asked if they used other people's wireless without asking, and if so, whether they felt any guilt over their actions (see Table 3). 
Table 3. Sentiment towards unauthorized wireless use and using other people's wireless signals.

Q36. "I don't mind if people use my wireless signal

without my knowledge." Do you agree or disagree

with this statement? $(\mathrm{N}=32)$

\begin{tabular}{ll}
\hline Agree & $8(25 \%)$ \\
No Opinion or Mixed Feelings & $6(19 \%)$ \\
Disagree & $18(56 \%)$
\end{tabular}

Q27. If you have used other people's wireless

signals before without their knowledge, how do you

generally feel about this? $(\mathrm{N}=28)$

\begin{tabular}{ll}
\hline Feelings of guilt & $9(32 \%)$ \\
Not sure & $1(3 \%)$ \\
No feelings of guilt & $18(65 \%)$ \\
\hline
\end{tabular}

Question 27 is an approximate gauge as to the feelings that respondents exhibit when it comes to using other people's wireless signals without permission. Most respondents seem to exhibit little or no guilt over doing this, even though it is an activity that three of the interviewees considered theft, stealing, or leeching. Some respondents seem able to justify such practices to themselves because they do not feel they are doing anything wrong. For example, as a comment to question 27, one of the participants wrote "I'm doing nothing illegal while on the Internet, and I only use it for urgent things", while another wrote "as long as I'm not $\mathrm{d} / \mathrm{l}$-ing [downloading] enough to affect their maximum $\mathrm{d} / \mathrm{l}$ [download] limit a month, or slowing down the provider, I don't think it's a big deal." Others even felt that not encrypting one's network was their own fault and they should bear the consequences, presumably in this case someone using it without permission. For example, one online questionnaire respondent commented that "people with wireless networks should have the knowledge to secure them from unauthorized use, or at least understand the risks." Another respondent went as far as to state that "everyone should know how to put on an encryption key, if not, it's public domain for public use."

Respondents also had an interesting view of permission when it comes to other people using their wireless networks. While many respondents seem more open to sharing if others ask first, that support drops dramatically when it comes to people using it without asking first. The discrepancy between question 27 and question 36 should also be noted. While $65 \%(\mathrm{~N}=28)$ of respondents felt little guilt when using other people's signals, nearly 55\% $(\mathrm{N}=33)$ disagreed with other people using their signal without permission. This may be interpreted as respondents being comfortable with sharing signals, just not their own. To further test this result, a Goodman and Kruskal coefficient of ordinal association (Gamma) test (see Freeman, 1965) was calculated for participant's responses to Q27 and Q36. The Gamma value was 0.456 , suggesting a moderate positive association between feelings towards participant's own unauthorized wireless Internet use and how they feel when other people use their wireless Internet without asking. It appears for the participants that as feelings of guilt increase towards using other people's wireless, participants seem to be more agreeable to other people using their wireless without asking. Conversely, this also means that participants who feel less guilty, are also more disagreeable about people using their wireless. However, some participants did also note an interest in trying to make their 
wireless activities more known, as well some interest in promoting community or neighbourhood initiatives (see Table 4).

Table 4. Sentiments about greater sharing awareness and desired shared network attributes.

Q39. "I would feel better about using other people's wireless signals if I could thank them or let them know that I was using it somehow." Do you agree or disagree with this statement? $(\mathrm{N}=30)$

\begin{tabular}{ll}
\hline Agree & $20(68 \%)$ \\
No opinion or mixed feelings & $5(16 \%)$ \\
Disagree & $5(16 \%)$
\end{tabular}

Q41. Assuming that your concerns about using a shared wireless network were addressed, what characteristics/conditions would be of interest to you? Select all that apply. $(\mathrm{N}=33)$

\begin{tabular}{lc}
\hline Reduced monthly cost & $27(82 \%)$ \\
Ability to access free signals from home & $22(67 \%)$ \\
Membership in a co-operative & $15(45 \%)$ \\
Local/community Internet content & $12(36 \%)$ \\
Promoting access for others in your neighbourhood $13(39 \%)$ \\
Not interested at all & $2(6 \%)$ \\
\hline
\end{tabular}

Question 39 suggests that most participants would be in favour of removing some of the anonymity of wireless sharing by being able to identify themselves or thank the person who is sharing their wireless signal. Question 41 also indicates some support for other neighbourly activities like promoting access for others, viewing local or community Internet content, and entering into co-operative membership for the service. However, more 'selfish' motivations were more appealing to participants, such as reduced monthly cost and accessing free wireless signals from home. Furthermore, participants also expressed reservations about paying for such characteristics.

\section{Discussion}

The findings from our research shed light on the prospects for two, quite different perspectives on wireless Internet use and sharing: that of the community-wide infrastructure; and local, ad-hoc sharing. While these two models are at extremes of the wireless Internet network deployment spectrum, with models such as hotspot access somewhere in the middle, they represent two key means of access.

\section{Infrastructure deployment}

The use of large-scale infrastructure based wireless systems can vary greatly from project to project and by no means should it be suggested that they will have a universal deployment. Municipal and community projects may be publicly owned and deployed with the service distributed like other utility services such as water or power. They may also be privately 
owned, with consumers subscribing to these services in much the same way they subscribe to their current ISPs. In this particular study, some questions posed to participants (Questions 40-42) dealt with a hypothetical shared wireless service which would be centrally administered by a provider. In this kind of arrangement the findings generally suggested that the key factors for participants in choosing a particular Internet service were reliability, security, privacy, and speed. To a lesser extent, lower costs were valuable too. What was interesting about our findings is that in a market like Toronto, dominated by two major Internet providers, participants were less concerned with the brand or the company providing the service, than with the functional aspects of the system. Furthermore, whether or not the system was deployed wirelessly instead of the more conventional wired service mattered only insofar as it affected reliability, speed, and privacy. However, it did also seem evident from participant's responses that subscribing to a service entailed certain expectations for good quality of service, as well as other typical service features such as technical support and customer service. Thus, the conclusion we draw from our research regarding wireless infrastructure adoption is that if the system is proposed to prospective users like any other ISP, even if wirelessly-based, consumers would then consider its adoption much as how they would choose between any service providers. Unless there were very clear advantages to the wireless service, the switching costs would likely discourage a change in provider.

\section{Local ad-hoc sharing}

The question of deploying networks in a local ad-hoc arrangement is arguably a more difficult proposition. In addition to being subject to the same concerns as infrastructure networking, there are other issues as well. While the deployment may be as simple as an individual deciding to open their wireless network for others to use, this may not be so easy a decision to make. Firstly, respondents seem primarily interested in a shared network service only in what it can do for them (e.g. things like reduced personal costs, better reliability of the connection, greater availability of signals, and so forth). Of course, this is an entirely predictable approach: there was never any expectation that respondents would put the needs of others in the community above their own or their households. Thus, if there is little perceived personal benefit to sharing, there will be great reluctance to share.

Secondly, the questionnaires and interviews probed existing wireless use to investigate participant's feelings towards these practices. We found a certain degree of comfort with the current tendency to use other's signals anonymously. Participants seemed to justify this behaviour by classifying their own use as harmless or innocent. As evidence, consider that more than half of the respondents to the long questionnaire felt little guilt over using other people's wireless signals without asking for permission. While there may be some interest in thanking or identifying oneself to the WiFi owner, on the other hand, this is not the same as entering into some systematic relationship, like a shared wireless system. For example, one of the researchers, in a friendly way, identified himself to his neighbour and mentioned that occasionally when he lost his own internet connection he would use this neighbour's wireless unencrypted high-speed connection as a back up. A few days later, the neighbour encrypted his signal, preventing any further 'back up' usage! Perhaps as an example of the kind of discrepancy between sharing for one's own use and sharing with others, the neighbour had even admitted to using other people's unprotected signals too.

As much as respondents may consider themselves open to neighbourhood or community participation, it is relevant to consider whether there may in fact be some deepseed reluctance to creating these new social networks. Deploying a shared network as an expressly community building exercise may start triggering the question amongst potential participants: "how well do I really want to know my neighbours?", at least if it requires involvement with people beyond ones immediate circle of acquaintances. Gans (1967, 1968, 
as quoted in Hampton \& Wellman, 2003) found that "in a traditional suburban community, the most viable relationships are the most physically accessible, generally between those who live in homes that are no more than three or four homes distant" (pg.297). As this is typically the range of consumer grade WiFi equipment, this could mean that one viable way for creating neighbourhood networks is to build up from very local cooperation arrangements. Hampton and Wellman (2003) also add that there may be psychological barriers to interacting with neighbours, specifically "a fear of embarrassment, a fear of giving offence, and a general fear of imposing on neighbour's commitments can also inhibit neighbouring" (pg.285). The results from our research seem to reflect these findings in that people seemed somewhat distant with their neighbours and only had selective contact with them.

People are often wary of the uncertain. Consider Kahneman and Tversky's (1979) Prospect Theory, which suggests that when it comes to decision-making, "outcomes which are obtained with certainty are overweighted relative to uncertain outcomes" (pg.268). In this case, leaving one's network open to use would definitely have uncertain outcomes. Participants seemed to lack trust in strangers, in that opening up a connection would be exposing oneself to too great a risk of negative effects. These might be impairment of one's speed/bandwidth, and the potential for hacking or other security and privacy concerns. Sharing one's own network means potentially exposing oneself to trouble for the vague benefit of others (i.e. you may not even know who is sharing with you). This may be a questionable value proposition for wireless users, which may explain the reluctance to share with others but the ease with which users take from others.

The importance the Internet plays in the every day lives of our respondents should not be underestimated when it comes to sharing a connection. Zaltman (2003) wrote that understanding the emotional benefits of a product or service was a strong component of consumer experience and that "for consumers, emotional benefits stem in part from the important values and themes that define and give meaning to their lives" (pg.18). For users for whom the Internet plays a significant role in daily life, perhaps fulfilling roles of communications tool, information source, as well as productivity and entertainment centre, interruptions may not be tolerated. Consider that $72 \%(\mathrm{~N}=33)$ of respondents agreed that wireless Internet was less reliable than wired Internet. Furthermore, $79 \% \quad(\mathrm{~N}=33)$ of respondents believed that sharing Internet connections impairs their speed/bandwidth. Our findings certainly suggest that the respondents are mostly individuals for whom Internet plays a key role in daily life. Not only did $81 \%(\mathrm{~N}=33)$ of long questionnaire respondents consider themselves at least moderate Internet users, but also $75 \%(\mathrm{~N}=33)$ of respondents strongly agreed that they would have a hard time adjusting to life at home without high speed Internet (Question 32). Enjoyment and fun for the user might also be supported through their ability to play online games, share files via Peer-to-Peer networking, or watch streaming video, for example, all activities which consume relatively large quantities of bandwidth. Indeed, what might contribute to reluctance to share is the belief that strangers may use an open network to

participate in these high bandwidth activities as well, which would impede shared network usage.

\section{Opportunities for sharing}

Of course, the reality is perhaps not so isolationist and cynical of neighbourhood and community participation through Internet sharing. Indeed, our sample was composed largely of individuals without clear connections or community ties (although these may have existed without our knowledge). Closely-knit communities where individuals know each other and have strong social ties may be less likely to experience problems such as free-riders or difficulty managing collective resources. For these kinds of communities, individuals may be 
comfortable with talking to others about their use of the collective resource. There may be enough existing respect for the shared nature of the connection to discourage potential abuse. Even so, individuals may be more tolerant of minor impairments to their connection when utilizing ad-hoc networks with friends and neighbours. Kavanaugh et al. (2005) wrote that their notion of community commitment is "related to an individual's sense of collective efficacy: the belief that members of the community can pull together and act effectively to foster desired change" (pg.13). If an individual has a strong sense of collective efficacy, they are more likely to put in more effort into a group endeavour, in this case, supporting wireless sharing.

On the other hand, in communities which are not close and composed more of strangers, collective efficacy may suffer and there may not be interest - or perhaps even distrustfulness - in sharing with neighbours. Since our data was collected from individuals who live in many different communities, it is not possible to ascribe any results to one community or another in particular. However, results from our questionnaires indicate a somewhat mixed picture on the specific topic of sharing. For example, when asked if they agree or disagree with the statement that "I think that other people sharing the same connection I use will diminish my Internet experience" $51 \%(\mathrm{~N}=33)$ agreed while $39 \%$ disagreed (10\% had no opinion or mixed feelings on the matter).

The permission questions also suggest some flexibility. Most respondents supported sharing if permission was asked. Similarly, most did not support unauthorized sharing. This suggests that there is some tolerance among respondents for sharing as long as it was an agreed upon arrangement. Importantly, an underlying theme among respondents amenable to sharing is that the additional use would need to be 'within reason.' This was defined, albeit anecdotally, as shared use that did not infringe on users' own access (e.g. they did not detect appreciable connection slow-down) and that usage is fairly prioritized (with the sharer having priority over the share-e). There was a distinct sense that sharing where others could dominate the connection was unacceptable to the individual making their signal available.

Among participants who generally viewed sharing negatively, there seemed to be some support for the practice. For example, one interviewee noted how 'silly' it seemed that in a high density apartment building, each tenant was paying $\$ 45 /$ month for Internet access when a few wireless routers would easily cover all of them. Another interviewee remarked that she had shared her connection with others in her building who she knew could not afford high speed themselves. Our results suggest that if users could be assured of the reliability of their connection and that their security and privacy were not in danger of being siphoned off via the airwaves, that sharing would be a much more viable option. This research then lends support for sharing models such as FON $^{1}$ and Wireless Nomad ${ }^{2}$ where one can choose to share with other members of FON or Wireless Nomad, respectively, while the service administration handles authentication and security/privacy. In these models, in exchange for sharing access from ones own wireless router, you too can access the signals hosted by other members of the network in a quid pro quo sharing arrangement.

Our research also highlights a number of design features that might promote sharing among infrastructure or ad-hoc networks. Notification or identification would be one, to encourage the sociality of wireless networking and remove some of the anonymity of connecting. This would be helpful to both the sharer (to know who was using their signal) and the share-e (to alert the sharer and perhaps thank them). Secondly, a prioritizing scheme of some sort would be necessary to alleviate concerns among the sharer that he or she would

\footnotetext{
${ }^{1}$ www.fon.com

${ }^{2}$ www.wirelessnomad.com
} 
be reduced to back-of-the-line access to their own router. Finally, given the current somewhat selfish perspectives among many respondents on sharing, there would have to be tangible benefit to the sharer beyond altruism or a sense of community participation. Costsharing, greater access to signals, and improved reliability would definitely constitute such benefits. Our research suggests that adopting such features would improve the prospects for sharing, even in urban neighbourhoods that were already well provisioned with Internet access.

\section{Conclusion}

Given the increasing interest and growth of wireless networking projects around the world and in Canada in particular, this research sought to investigate how well a shared model of household Internet provision using wireless technology would work in a residential Canadian neighbourhood. Toronto was selected based on proximity and on the existing prevalence of wireless technology and high speed Internet access. A significant part of the motivation for this project was recognizing the advantages and benefits proposed by wireless advocates and reconciling that with the actual interest in adopting the technology among residential users of varied backgrounds. Particularly since the existing model of household Internet provision relies on single households acquiring services on their own for their own use, a shared model especially would be a distinctly different approach, not just in a technical and financial sense, but in a social one as well.

The findings from our research provide useful insights about Internet usage and attitudes towards wireless. The results suggest that respondents highly value Internet access and that for many it has become heavily integrated into their daily lives. Furthermore, respondents placed much value on the mobility and freedom they received from wireless access, not only in their own homes, but when on the move at friend's homes or in the city. Respondents generally seemed positive towards shared wireless Internet in their neighbourhoods, but unsurprisingly, had a number of concerns about how such a service would be deployed, administered, and operated. In particular, for local, ad-hoc sharing it was an important question as to what kind of benefit people who share could expect and at what costs. While currently there seems to be only vague benefits, outweighed by some wellrecognized risks, for sharers who simply open their wireless signals for all others to use, our findings do suggest a number of design features which, if incorporated into future wireless networks, might promote sharing and create some more tangible benefits for sharers. In addition to ensuring the reliability, security, and privacy of an individual's connection, design features could include a notification/identification system, a prioritizing scheme to preserve dominant access to the sharer, redundant signal coverage, and a cost-sharing arrangement. Incorporating such features may go a long way to reassuring concerns that wireless users have over sharing and may improve the viability of wireless networking projects.

There are a number of limitations to this study, notably the small sample size and general lack of demographic diversity of that sample. As a result, readers should exercise caution in generalizing any conclusions found in this study to other communities and/or wireless experiences. However, while it may be the case that our sample is biased towards highly-educated, Internet savvy users, it is important to consider these individuals' opinions particularly because they may be leading adopters of wireless technology and they may affect others as change agents within their spheres of influence.

Indeed, there is much work to be done in this field as new city WiFi deployments are announced and commercial wireless technology becomes more ubiquitous. It will become 
important, above and beyond the technical aspects of deploying shared networks, to understand the social dynamics of these networks and how potential users would feel about adopting them. As our study highlighted, people certainly hold a variety of opinions when it comes to wireless Internet and sharing. 


\section{References}

Akyildiz, I. \& Xudong, W. (2005). A survey on wireless mesh networks. Communications Magazine, IEEE, 43(9).

Andersen, E. (2003). Genesis of an anthill: wireless technology and self-organizing systems. Ubiquity, 3(49).

Casalegno, F. (2001). On cybersocialities. Networked communication and social interaction in the wired city of Blacksburg, VA, USA. Telematics and Informatics, 18(1), pg.17-34.

Civille, R., Bieber, M., Gurstein, M., Kolko, B., Silver, D. \& White, N. (2002). A Vision for Virtual Community Informatics. Unpublished manuscript. Retrieved September 10, 2006 from: http://is.njit.edu/vci/vci-white-paper.doc

Chukwuma, U., Furnell, S. \& Ghita, B. (2002). Assessing the global accessibility of the Internet. Internet Research: Electronic Networking Applications and Policy, 12(4).

Damsgaard, J., Parikh, M. \& Rao, B. (2006). Wireless commons perils in the common good. Communications of the ACM, 49(2).

Dryburgh, H. (2001). Changing our ways: Why and how Canadians use the Internet. Statistics Canada, Ottawa, ON., Catalogue no. 56F0006XIE. Retrieved August 12, 2006 from: http://www.statcan.ca/english/research/56F0006XIE/56F0006XIE.pdf

Freeman, L.C. (1965). Elementary Applied Statistics: For Students in Behavioral Science. John Wiley \& Sons, Inc. NY, USA.

Frieden, R. (1997). Widespread deployment of wireless telephony: Business, legal, regulatory and spectrum challenges. Telecommunications Policy, 21(5).

Goth, G. (2005). Muncipal Wireless Networks Open new Access and Old Debates. IEEE Internet Computing, 9(3).

Gibbons, J. \& Ruth, S. (2006). Municipal Wi-Fi: Big Wave or Wipeout? IEEE Internet Computing, 10(3), pg.66-71.

Hampton, K. \& Wellman, B. 92003). Neighboring in Netville: How the Internet Supports Community and Social Capital in a Wired Suburb. City and Community, 2(4), pg.277311.

James, J. (2001). Low-cost computing and related ways of overcoming the global digital divide. Journal of Information Science, 27(6). 
Kahneman, D. \& Tversky, A. (1979). Prospect Theory: An Analysis of Decision under Risk. Econometrica, 47(2), pg.263-292.

Kavanaugh, A., Carroll, J.M., Rosson, M.B. Reese, D.D. \& Zin, T.T. (2005). Participating in civil society: the case of networked communities. Interacting with Computers, 17(1), pg.9-33.

Lentz, R.G. (1998). Corporations vs. communities: Evolution of wireless services in the US and the devolution of local control. Telecommunications Policy, 22(10).

Marks, R.B. Gifford, I.C. \& O'Hara, B. (2001). Standards in IEEE 802 unleash the wireless Internet. Microwave Magazine, IEEE, 2(2).

Pae, J.H. \& Hyun, J.S. (2006). Technology advancement strategy on patronage decisions: the role of switching costs in high-technology markets. Omega, 34(1), pg.19-27.

Remondo, D. \& Niemegeers, I. (2002). Ad hoc networking in future wireless communications. Computer Communications, 26(1).

Rogers, E.M. (2003). Diffusion of Innovations, Fifth Edition. Simon and Shuster, New York, NY.

Sandvig, C. (2004). An initial assessment of cooperative action in Wi-Fi networking. Telecommunications Policy, 28(7-8).

Schmidt, T. \& Townsend, A. (2003). Why Wi-Fi wants to be free. Communications of the ACM, 46(5).

Shah, R.C. \& Sandvig, C. (2005). Software Defaults as De Facto Regulation: The Case of Wireless APs. Paper Presented to the $33^{\text {rd }}$ Research Conference on Communication, Information and Internet Policy, Arlington, Virginia, USA, September 23, 2005. Retrieved November 10, 2006 from: http://web.si.umich.edu/tprc/papers/2005/427/TPRC\%20Wireless\%20Defaults.pdf

Souter, D. (1999). The role of information and communication technologies in democratic government. Info, 1(5).

Tapia, A.H. \& Ortiz, J.A. (2006). Municipal Responses to State-Level Broadband Internet Policy. Paper Presented at the $34^{\text {th }}$ Research Conference on Communication, Information and Internet Policy, Telecommunications Policy Research Conference, Arlington, Virginia, USA. Retrieved November 10, 2006 from: http://web.si.umich.edu/tprc/papers/2006/554/TPRCfinal_pdf.pdf

Tully, J. \& Riekstins, A. (1999). License-free wireless internet access technologies. Computer Networks, 31(21).

Vos, E. (2005). MuniWireless.com Second Anniversary Report, July 2005. Unpublished report. Retrieved August 25, 2005 from: http://muniwireless.com/reports/docs/July2005report.pdf 
Williamson, K. (1999). Extending universal service: social and economic issues. Info, 1(2).

Wu, I. (2004). Canada, South Korea, Netherlands and Sweden: regulatory implications of the convergence of telecommunications, broadcasting and Internet services.

Telecommunications Policy, 28(1).

Zaltman, G. (2003). How Customers Think: Essential Insights into the Mind of the Market. Harvard Business School Press, MA. 